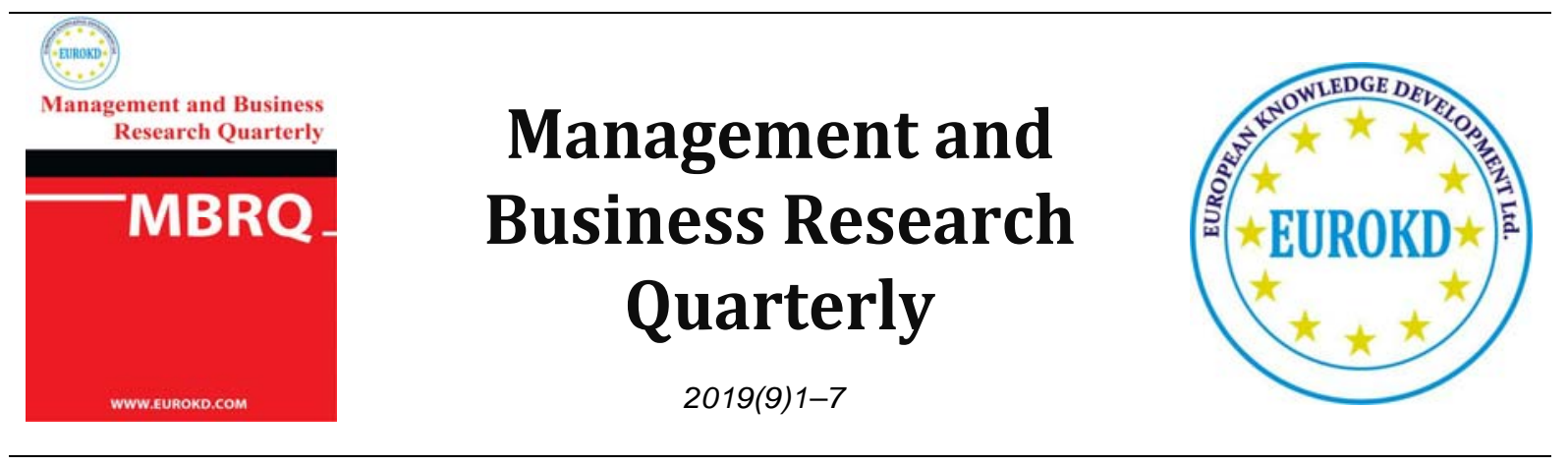

\title{
World Economic Crisis and Its Influence on the World Economic Development
}

\author{
Medea Shapatava \\ Faculty of Economy and Business, Tbilisi State University, Georgia
}

Received 27 March 2019

Accepted 21 May 2019

\begin{abstract}
Contemporary world admits and analyses the destroying results and consequences of the largestever the bankruptcy of the Lehman Brothers Investment bank which lead to the mortgage crisis and turned into the global one. The recession continues up to present, i.e. almost for ten years. Leading economists forecast the further negative issues and confess that the economic figures would never go back to the ones we had back ten years ago. The extreme points of consideration the recession and the crisis issues are in contradiction with the economic theory which predicts further recession though may never provide consistent and exact figures and dates. The reflection of the crisis onto the economic theory, science and on the real picture may provide further materials for discussions and arguments against existence of the crisis, as the global economy development never interrupted. Moreover, the world faced the birth of an absolutely new and enigmatic product on the market - cryptocurrency. The question is: would the cryptocurrency bring the relief in terms of recession or would it lead to a new default of the market. The economic science estimates the pros and cons of the existing risks and market threats and hopefully will play its substantial role in eliminating them.
\end{abstract}

Keywords: Global Economic Crisis, Economic Science, Cryptocurrency.

\section{Introduction}

Contemporary Economic science does not exist separately from the society. The society creates economy and economy itself interacts with the endless demands of the society. This mutual 
interaction creates subsequent action of the both. As a consequence of this interaction we received a current state which due to certain conditions and certain period of time created phenomena named Crisis.

It seems natural that there is no sphere during crisis occurrence where this crisis is not reflected. Primarily, economic crisis finds its own reflection inside its scientific nature. It is a paradox and meanwhile natural that very often it takes many years to study and make conclusions about existing crisis. The economic crisis exactly as a nature has repeating cycles which return after certain period of time. This is connected to the unusual "Natural" characterizing feature of the crisis.

In Economy statistic figures represent the basis for the scientific hypotheses, calculations and forecasting. Unfortunately that is a fault of statistics that many important exceptions remain neglected as so-called "outliers" are being considered not so much important. They and the outcomes they may bring are not specified and learned attentively due to their insignificant figures. This inattention creates mistakes which bring us to the certain crisis situations (for instance, if we take some system failure probability as a $1 \%$, we do not discuss its reparation. This malfunction may create breakage of some bigger system or the whole process termination).

\section{The Subject of the Problem}

In contemporary world there would not be expressed so many arguing opinions and reflections about paradigm research if not the global nature of the crisis and its vitality during long period. Nobody would have imagined in far 2008 that the bankruptcy of Lehman Brothers investment bank would become the beginning of a worldwide crisis so much prolonged in time.

Existing recession involuntarily supports not only the globalization but also successful spread of the faults and blemishes, copied solutions of those faults by the countries. As a result we get the reflections of crisis in almost all spheres. If we look at the crisis using our imagination we could compare it to a cancerous tumor whose cells are developing quite actively and they are spreading to all of the parts of the body and its organs. In this case we can imagine the economics as a central and live body. The vitality of this body is supported by the economists of different countries and their decisions.

In order to discuss the main topic let us as an ad hoc suggest/change the problem and imagine the current state of economy not as a crisis, but as its natural condition. What do we mean in this condition: if we take as a null hypothesis (or the zero point) not the existing crisis situation, but we consider it to be its natural condition.

As we mentioned before statistics almost neglects exceptions as not massive examples given in figures. To continue our suggestion we may disregard the crisis (as a result) and seek for the solution of the problem in its existing state. Let us not name it a "crisis" but let us call it "natural". If further we try to discuss economic crisis and its reflection on the economic science and the practical side, we will get the conclusion that the ways for the solution are similar in both situations (other things being equal): whether we have the crisis or we have in our imagination its "non-existence" state. The ways for its solution are similar and the further action plans look more or less similar.

In one of his famous articles leading Nobel Prize winner economist Paul Krugman expresses his point of view towards accusation of US in "Economic Hooliganism". USA is being accused in 
supporting inflation via "printing too much money". Paul Krugman's response to accusations is simple: he insists that such countries like China, Russia and Brazil own instruments and tools to tighten and slow-down the inflation (Paul Krugman (2011). Inflation and Economic Hooliganism. New York Times Magazine, May, 11). There is born a question: if there really exist such instruments then why the countries do not use them? Instead, we use different ways in different countries, besides, we use even well-known inflation targeting tool. Besides, we would love to put a question which nobody dares to put to American economists: why the US did not feel obliged or responsible for the initiation (probably unforeseen and involuntary but still) of the global crisis. Not only they took or felt this responsibility they even complicated the situation whilst prolonged recession period US started USD strengthening process. This in real overcomplicated the global economic picture. One of the most important currencies of the world strengthened at the expense of the dependent countries. Unfortunately this is not a fair solution. For the professor Krugman the way is clear: the economic policy according to him should be concerned about jobs. There is no ambition from our side to argue with the Nobel Prize winner at this stage but if there existed "usable" active tools then any country would use them and it would be very easy to manage inflation. We would solve a lot of economic problems. Although we should absolutely agree with his idea of employment and creation of jobs as these are the main tasks for resisting the crisis: economic policy should widely support employment.

We should not suggest other ways to solve the problem neither in artificial nor managed or natural crisis. The jobs are not being created without increasing the production or boosting service volumes. So the main task is increasing them constantly.

If we disregard the outstanding position of various countries due to their nuclear and cosmic potential while they are using this potential very effectively in the political point of view, then the economies of all the countries are alive and all of them have a chance to become developed and high-technological producing countries. Let us discuss what kind of solution may be found in this case.

We should agree with another Nobel prize-winner economist, Prof. J. Tirole in his vision of economics as a moral and philosophical science. (J. Tirole, "Global Challenges, the Economist, and the Common Good"; Following the Results of the V International Forum at the financial University, https://financetp.fa.ru/jour/article/view/814/538). "Primarily economics is a challenge for politicians for them to be very careful in economic policies of certain countries... ". This is exactly what we are trying to escape meaning to neglect different dangerous outstanding potentials of various countries. We will discuss political decisions later.

Consequently with the crisis there are being created new products such as cryptocurrency. The operation of this novelty is almost absolutely non-transparent and its future is absolutely undefined. Although the creation of cryptocurrency provided us with the example that any developing or economically weak country may become the leader in innovation technologies. During the global recession our country - Georgia is a leader in crypto-mining. Unfortunately, this sphere is not being regulated by central authorities and we do not obtain exact figures about position of Georgia, but it is clear that Georgia is a leader on this market. 
It would be interesting to draw our attention to the relations between two biggest economies: China and USA and to the political tension between them. Namely, we should recall the tariffs created by the order of President Trump on China steel and aluminum and farther barriers created by USA to China (https://www.project-syndicate.org/commentary/trump-china-avoiding-trade-war-by-shangjin-wei-2018-03?utm_source $=$ Project $\% 20$ Syndicate $\% 20$ Newsletter\&utm campaign $=2$ e12931ef4sunday newsletter $25 \quad 3$ 2018\&utm medium $=$ email\&utm term $=0$ 73bad5b7dd8-2e12931 ef4-

93567601\&barrier=accesspaylog). This happens whilst the import of China to USA in 2016 consisted of $21,1 \%$ of the whole import volume and China was the main trade partner to USA with the turnover of $\$ 578,2$ in 2016 . The export of goods from USA was $\$ 115,6$ bln while the import was $\$ 462,6 \mathrm{bln}$. The trade deficit between USA and China shows us a figure of $\$ 347 \mathrm{bln}$ (https://ustr.gov/countries-regions/china-mongolia-taiwan/peoples-republic-china). Logically the US production facilities which used China steel and aluminum have to use the materials presented on the domestic market. This will increase their price. Though if we look from the other side there is one positive issue: within tougher competition China companies will have to look for more economically efficient and technologically new materials and this will cause development of this sphere. So Mr Trumps' initiative has got two sides. Whilst he is concerned about domestic market development he unconsciously helps to develop China economy.

We should not hurry with conclusions when we look at Georgian humble domestic market. As we address Georgian economy as an open economy example we are not secured from the numerous risks connected to the open-type economy. In risks we consider the period of time when Georgia continues consuming importing products and meanwhile increases domestic production and new technologies implementation \& development. From this point we may track the reflection of crisis on the economy of Georgia. Primarily we should mention negative trade balance according to Jan 2019 - \$349.2 mln. (Preliminary data: www.geostat.ge).

Imported goods create the idea of the quality of goods to the majority of customers. The main goal for Georgian producers is to equalize the quality level of goods with the worldwide production. This will never happen if the domestic production technologies, goods and services do not catchup with the world standard. We will not be able to mention domestic products (besides Georgian famous wine) which comply with the world market standards. Comparably good results are present at the service/tourism market where Georgian traditional hospitality played its important role. This positive feature created its input into Georgian GDP.

\section{Acknowledgement and Approaches}

We would like to take an unbiased view to the tendencies. On the basis of the precise analyses the biggest problem and meanwhile the comparative freedom in praising the economic science and the influence consists of the given statement that economic is not an exact science. We may use indicators measurement methods, statistics and mathematics, though we may only predict some occurrences. We may not ever be able to provide exact result in figures. It should be admitted that the economists do not own certain tool or mechanism, exact formula to be able to eliminate or improve certain undesired mistakes or gaps immediately. Hence, endless conversations are useless about world crisis which was not predicted and starting from 2008 lies as a shadow over all the 
countries. Probably the crisis of 2008 was a natural phenomenon or the end of cycle and controversially it gave the beginning to a new development and new thoughts regarding predicting economic events.

After bankruptcy of Lehman Brothers in 2008 there were offered hundreds of plans, stimulus packages, reforms, though no one could reverse the global process. During recent decade world leading economists, think tank companies try to use their best resources to defeat the recession though its negative results are still present. The worst is that there began tension between two largest economies of the world - USA and China. The world economic climate indicators seemingly dropped in the beginning of 2018 (https://www.cesifo-group.de/DocDL/WES_2_18.pdf) and experts forecasts for the future became more pessimistic.

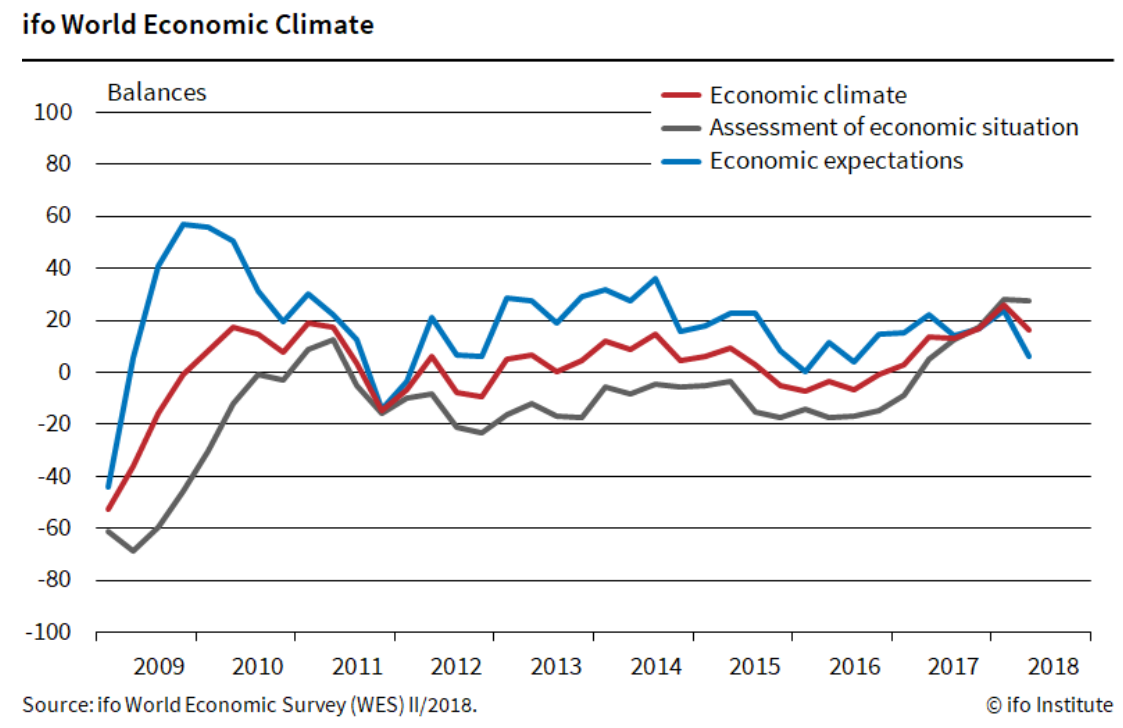

According to the experts opinions the indicators will never return to the figures we had before 2008 . Some economists may forecast the quick recovery from the recession though on the last-year influential economic forum in Davos we observed opinions that we are "in the end of tunnel" and probably the crisis will end soon, though this eyar we did not notice more optimism. No one scientist may provide us with the exact date and name the country from where the recession end will begin and which event will give the start to the end of the recession.

Despite pessimism, development of the world is obvious. Subsequently we read numerous experts' opinions that the world approaches the crisis which will be much more complicated and destroying for the world than the one we witnessed in 2008 (Mark Kolakowski | January 15, 2018; 5 Global Risks That Could Hammer Stocks in 2018). Some part of economists name cryptocurrency market unprecedented capitalization, enormous investments into this sphere and complex nature of the cryptocurrency and blockchain technologies as a threat for creation of a new crisis. The capitalization of this market is obviously unprecedented and creates a certain "speculative" capital 
bubble. The situation is becoming more complicated if we regard this sphere as a part of huge shadow economy (figures may be found on the site: https://www.ccn.com/marketcap/)

If the world market suffers from the crisis then why a new enigmatic product created by anonimous person or entity develops so rapidly and regularly? This happens when this monster of enormous capitalization called Virtual Currency practically is not being regulated and managed by any of government authorities. If we compare this eventual development to the global hysteria around crisis this should provide a good material for reflections on the cryptocurrency. To express it idiomatically, the new product represents "unknown body" about which we may not have any unequivocal opinion. Moreover, we may not be able to provide any positive or negative prospects. It is possible that cryptocurrency was created to absorb existing crisis and bring us to a new, biggerscale crisis or vice-versa, despite all the enigmatic characteristics cryptocurrency will become a new swift platform where the world economy will move smoothly and thus will be saved in a safe environment based on the new playing rules.

There is one more version: it is possible that cryptocurrency and blockchain technology was created as an alternative to the default and in real there does not exist any crisis. There exists only covered threat that cryptocurrency is developing in its own virtual space and virtual market apart from the real economic markets in order to regulate world economy for the virtual market benefits. The fact is that we do not have exact answer to all these suggestions and we may be absolutely mistaken in our attempts to make forecasts.

\section{Economic Science VS Economic Crisis Evaluation}

We would like to return to the evaluation of economic science crisis. Economic science as a theory does not represent a real tool which can affect live economy if we consider the economy as a live and constantly changing organism. The role of the economic science is to calculate and predict some events. Evaluate the results, though the results which already happened and exist. As we mentioned above, in this philosophical science (despite statistical and mathematical models existence) we may never predict exact figures. We may predict only occurrences of some events, not the figures. Based on this assumption we may not prove that economic science is in crisis. The science does not suffer of any crisis. The crisis exists in the live organism - economic - which reacts to constant events, conditions and practical methods though as mentioned above, no statistic table is able to provide exact figures of sudden occurrences. These sudden occurrences were discussed before as the exceptions which are usually neglected in statistic calculations. This in no way means that we should admit that the economic science is in crisis and we should not look for the solutions to end the recession. In both cases the solution is one: work, observe events, research and again and again, calculate to predict. Further we will only be able to compare the forecast to the real results in order to analyze the mistakes for their maximum avoidance.

Economy demands figures, accuracy of data, balance, global transparency but unfortunately in today's world there exists certain double-standard when it is acceptable to witness creation of a global product (project) by anonymous entity. And this product is not a subject to regulation by international standards. This creates many questions whilst all the countries are obliged to regulate 
their own currencies according to the international standards. And yet it is unclear to whose benefit will work this strange double standard in future.

\section{Conclusion}

It would be acceptable to admit the crisis in economic science if the economic processes suffered from stagnation. We must admit that the global crisis gave impetus to improve research and all the spheres are mobilized to develop, to resist imperfections. The economy does not exist on the flat surface. It is an eclectic unity for the world which researches and learns constantly and it is aimed to form a solid and high-scale imrpoved contemporary model.

We may share or not Great Thinker, Karl Marx's point of view regarding cycle nature of crisis. We may agree or disagree that crises are characterized by cyclic nature and thus they are repeating. This is not in contradiction with the above discussed. Crises contribute to creation of a new ascending generation period and increase in production. Thus the cyclic process generates the same overproduction which brings the countries back to the crisis. The solution according to Marx suggests work and development. This way meaning other thing being equal provides us with the opportunity to create a healthy economy.

\section{References}

Papava V., Charaia V., (2017). Inflation Index Modifications and Expediency of their Application for Georgia. Expert Opinion \#77; https://www.gfsis.org/files/library/opinion-papers/77-expert-opinion-eng.pdf

Papava V., (2009). Georgian Economy: Faults, Threats, the solutions. Crisis of 2008 in Georgia: Preconditions, Reality, Prospective. Tbilisi: Independent Experts Club. http://www.papava.info/publications/krizisi-2008-geo.pdf

Paul Krugman (2011). Inflation and Economic Hooliganism. New York Times Magazine, May, 11. https://www.nytimes.com/2011/05/15/magazine/paul-krugman-how-the-financial-crisis-was-wasted.html>

Office of the United States Trade Representative; Executive office of the President. U.S.-China Trade Facts.

https://ustr.gov/countries-regions/china-mongolia-taiwan/peoples-republic-china

Cryptocurrency marketcap: https:/www.ccn.com/marketcap/

Edmund L. Andrews \& Eric Dash (March 23, 2009). “U.S. Expands Plan to Buy Banks’ Troubled Assets”. New York Times

http://www.nytimes.com/2009/03/24/business/economy/24bailout.html? r=2\&adxnnl=1\&adxnnlx=1244664011$\operatorname{lgbvYL}+$ QOw9VQsKrjV68kQ

Asma Salman and Muthanna G. Abdul Razzaq (January, 17, 2018); Bitcoin and the World of digital Currencies.

https://www.researchgate.net/publication/322553917

Vance Barse D., (March, 6, 2018); Remembering 2008: Portfolio Considerations for Volatile Markets. Executive Forums.

https://www.executiveforums.com/single-post/2018/03/05/Remembering-2008-Portfolio-Considerations-for-Volatile-Markets

Socialist voice (1983) Karl Marx and the World Crisis. No. $19 . \quad$ New York. Published by the League for the Revolutionary Party. 